\title{
Recuperação em área de empréstimo usada para construção de usina hidrelétrica
}

\author{
Marlene C. Alves ${ }^{1}$, Vagner do Nascimento ${ }^{2}$ \& Zigomar M. de Souza ${ }^{3}$
}

\begin{abstract}
RESUMO
A recuperação de áreas de empréstimo usada para construção de hidrelétricas é um processo lento que requer o uso de plantas de cobertura, como fonte de matéria orgânica e a aplicação de nutrientes e corretivos como condicionadores dos atributos do solo. Portanto, objetivou-se, com este trabalho, estudar a recuperação de atributos físicos do subsolo de um Latossolo Vermelho distrófico, utilizado no terrapleno e fundação da Usina Hidrelétrica de Ilha Solteira, SP. O delineamento utilizado foi em blocos casualizados com oito tratamentos e quatro repetições. A pesquisa foi implantada em 1992. Os tratamentos se constituíram do uso de adubos verdes, braquiária e correção do solo. Após 13 anos foram avaliados: porosidade total do solo, macroporosidade, microporosidade, densidade do solo, estabilidade de agregados, resistência do solo à penetração, teor de matéria orgânica e produção de matéria seca da braquiária. Os tratamentos adotados estão recuperando, de forma lenta, os atributos físicos do subsolo exposto. Os efeitos da recuperação do solo estão atingindo a profundidade de 0-0,10 m.
\end{abstract}

Palavras-chave: área degradada, adubos verde, pastagem

\section{Recovery of nativa area used for construction of hydroelectric power station}

\begin{abstract}
The recovery of native area used in hydroelectric power station construction is a slow process, and it requires the use of covering plant as a source of organic matter, application of nutrients and amendments as soil conditioner. Thus, this study has the objective to study the recovery of physical attribute of subsoil in a distrophic Red Latosol, used in the embankment and foundation of Hydroelectric Power Station, Ilha Solteira, São Paulo, Brazil. The design used was randomized blocks with eight treatments and four replications. The research started in 1992. The treatments consisted of green manure, pasture and soil amendment. After 13 years, total porosity, macroporosity, microporosity, bulk density, aggregate stability, resistance to penetration, organic matter of soil and dry matter of pasture production were evaluated. The adopted treatments are slowly contributing towards recovery of physical attributes of exposed subsoil. The effects of the soil recovery are reaching 0-0.10 $\mathrm{m}$ depth.
\end{abstract}

Key words: degraded area, green manure, pasture 


\section{INTRODUÇÃO}

Estima-se que mais de 200 milhões de hectares de solo são degradado no Brasil. Ações como mineração, construção de estradas, métodos agropecuários impróprios, construções de hidroelétricas e áreas industriais, entre outras ações, resultam em impacto imediato sobre os atributos físicos, químicos e biológicos do solo (Aquino et al., 2008).

As obras de engenharia, como a construção de hidrelétricas, rodovias, mineração e outros projetos desenvolvimentistas, em que ocorre remoção total da camada vegetal para a exploração do subsolo, dão origem às chamadas áreas de empréstimo (Alves \& Souza, 2008). Esta situação modifica as condições edafoclimáticas da área; entretanto, ao avaliar a extensão da degradação causada verifica-se que ela é mínima, comparada ao desmatamento ou ao superpastejo.

As áreas de empréstimo se constituem em um ecossistema degradado visto que tiveram eliminados, juntamente com a vegetação, seus meios de regeneração bióticos como o banco de sementes, banco de plântulas, chuvas de sementes e rebrota. Apresenta, portanto, baixa resiliência, isto é, seu retorno ao estado anterior pode não ocorrer ou ser extremamente lento (Chada et al., 2004). Para a recuperação é preciso selecionar e identificar espécies aptas às novas condições edáficas e que, de forma rápida, acelerem a estruturação e a formação dos horizontes mais superficiais do solo (Campos \& Alves, 2006). A adaptação e o desenvolvimento dessas espécies dependerão das condições físicas, químicas, biológicas e hídricas do solo além das condições do microclima local.

A degradação das áreas de empréstimo consiste na remoção da vegetação original e na retirada da camada superficial do solo, expondo o horizonte $\mathrm{C}$ e causando compactação, perda de matéria orgânica e baixa disponibilidade de nutrientes, em que o substrato resultante não permite o desenvolvimento da regeneração natural da vegetação. A degradação dessas áreas resulta em efeitos deletérios sobre os mananciais hídricos e a fauna local (Ferreira et al., 2007). Alcântara et al. (2000), apontam os estudos sobre solos como ponto relevante para a regeneração dos ecossistemas tropicais e subtropicais, devendo ser considerados para o melhor entendimento e planejamento dos processos ecológicos.

O problema de degradação da área em estudo foi gerado em consequência da construção da Usina Hidrelétrica de Ilha Solteira, SP. Entre as áreas onde o processo de degradação é mais gritante se encontram as áreas de empréstimo; são áreas com intensos sinais de degradação que, apesar de não sofrerem intervenções há 30 anos, apresentam regeneração natural insignificante (Rodrigues et al., 2007).

A revegetação de obras de barragem requer técnicas adequadas, sendo importante observar a interação positiva entre adubação mineral e adubação verde visto que nessas áreas foram removidas toda a vegetação e a camada fértil do solo (Campos et al., 2011). Rodrigues et al. (2007) observaram, estudando a dinâmica da regeneração do subsolo de áreas degradadas dentro do bioma cerrado, que as coberturas vegetais utilizadas na revegetação do subsolo estudado modificaram os atributos físicos e químicos e que o Pinus não foi uma boa espécie para recuperar os atributos do solo.
A degradação dos solos constitui um prejuízo socioeconômico para as gerações atuais e representa enorme risco para as gerações futuras. Portanto, este trabalho foi realizado com o objetivo de estudar a recuperação de atributos físicos do subsolo de um Latossolo Vermelho distrófico, utilizado no terrapleno e fundação da Usina Hidrelétrica de Ilha Solteira, SP.

\section{MATERIAL E MÉTODOS}

A área de estudo localiza-se no Planalto da Bacia Sedimentar do Paraná, situada na margem direita do rio Paraná, no município de Selvíria, MS, localizada nas coordenadas geográficas $20^{\circ}$ 22' de latitude Sul e 51 $22^{\circ}$ ' de longitude Oeste, com altitude média de $335 \mathrm{~m}$. O tipo climático é o Aw, caracterizado como tropical úmido com estação chuvosa no verão e seca no inverno, estando a umidade relativa dos meses mais chuvosos entre 60 e $80 \%$ (Köppen, 1931), apresenta declives muito suaves, relevo plano a suavemente ondulado. Segundo Demattê (1980) o solo original foi classificado como Latossolo Vermelho-Escuro álico, textura média e muito profundo; sua fração argila é de baixa atividade dominada, essencialmente pelas gibbsita e caulinita. Com base na nomenclatura atual foi classificado como um Latossolo Vermelho distrófico textura franco-argilo arenosa (EMBRAPA, 2006).

O delineamento experimental foi em blocos casualizados com oito tratamentos e quatro repetições. Cada parcela continha 10 x $10 \mathrm{~m}$ de dimensão e os blocos estavam 2,0 m espaçados entre si. Os tratamentos utilizados foram: $\mathrm{T}_{1}$ - testemunha (solo exposto); $\mathrm{T}_{2}$ - solo mobilizado; $\mathrm{T}_{3}$ - mucuna-preta (MP); $\mathrm{T}_{4}$ guandu até 1994, substituído por feijão-de-porco $(\mathrm{G} / \mathrm{F}) ; \mathrm{T}_{5}$ calcário + mucuna-preta $(\mathrm{C}+\mathrm{MP}) ; \mathrm{T}_{6}$ - calcário + guandu até 1994, substituído por feijão-de-porco $(\mathrm{C}+\mathrm{G} / \mathrm{F}) ; \mathrm{T}_{7}$ - calcário + gesso + mucuna preta $(\mathrm{C}+\mathrm{Ge}+\mathrm{MP})$ e $\mathrm{T}_{8}$ - calcário + gesso + guandu até 1994, substituído por feijão-de-porco $(\mathrm{C}+\mathrm{Ge}+\mathrm{G} /$ F). As espécies de adubo verde mucuna preta (Stizolobium aterrimum Piper \& Tracy), guandu (Cajanus cajan (L.) Millsp) e feijão-de-porco (Canavalia ensiformis (L.) DC), foram semeadas em dezembro e janeiro de cada ano e no início do florescimento eram roçadas e deixadas na superfície.

A usina Hidrelétrica de Ilha Solteira, SP, iniciou sua construção na década de 60. Da área em estudo foi retirada uma camada de 8,60 m do perfil do solo original para a fundação da barragem. A pesquisa teve início em 1992, sendo realizadas a caracterização química do solo (Tabela 1) e a física (Tabela 2).

Realizou-se, no início da pesquisa, a subsolagem da área, atingindo a profundidade média de $0,40 \mathrm{~m}$. O preparo do solo durante o período de estudo foi efetuado com uma aração, utilizando-se arado de aivecas, tracionado por um trator de 110 cv de potência. Após esta operação realizou-se uma gradagem niveladora usando-se grade de arrasto acoplada a um trator de $85 \mathrm{cv}$. A semeadura das espécies foi realizada manualmente, porém, os sulcos foram feitos por um conjunto composto por trator de $75 \mathrm{cv}$ de potência e sulcador. Os sulcos possuíam dimensão da ordem de $0,50 \mathrm{~m}$ entre linhas e $0,10 \mathrm{~m}$ de profundidade. A densidade de semeadura dos adubos verdes foi de 10 sementes por metro linear. 
Tabela 1. Análise química do solo exposto, realizada antes da implantação do experimento

\begin{tabular}{|c|c|c|c|c|c|c|c|c|c|c|}
\hline \multirow{2}{*}{$\begin{array}{c}\text { Profundidade } \\
\text { m }\end{array}$} & \multirow{2}{*}{$\underset{\mathrm{mg} \mathrm{dm}}{P}$} & \multirow{2}{*}{$\begin{array}{l}\mathrm{MO} \\
\mathrm{g} \mathrm{dm}^{-3}\end{array}$} & \multirow{2}{*}{$\mathrm{pH}$} & $\mathrm{K}^{+}$ & $\mathrm{Ca}^{2+}$ & $\mathrm{Mg}^{2+}$ & $\mathrm{H}+\mathrm{Al}$ & SB & CTC & \multirow{2}{*}{$\begin{array}{l}\mathbf{V} \\
\%\end{array}$} \\
\hline & & & & \multicolumn{6}{|c|}{$\mathrm{mmol}_{\mathrm{c}} \mathrm{dm}^{-3}$} & \\
\hline $0-0,20$ & 1 & 7,0 & 4,0 & 0,2 & 2,0 & 1,0 & 20,0 & 3,2 & 23,2 & 14 \\
\hline $0,20-0,40$ & 0 & 4,0 & 4,2 & 0,2 & 2,0 & 1,0 & 20,0 & 3,2 & 23,2 & 14 \\
\hline
\end{tabular}

P - fósforo disponível; $\mathrm{MO}$ - matéria orgânica; $\mathrm{pH} \mathrm{CaCl}_{2}$ - acidez; $\mathrm{K}^{+}$- potássio; $\mathrm{Ca}^{2+}$ - cálcio; $\mathrm{Mg}^{2+}$ - magnésio trocáveis; $\mathrm{H}+\mathrm{Al}$ - acidez potencial; SB - soma de bases; $\mathrm{CTC}$ - capacidade de troca catiônica; $\mathrm{V}$ - saturação por bases

Tabela 2. Valores médios do teor de matéria orgânica $\left(\mathrm{g} \mathrm{dm}^{-3}\right)$, porosidade total $\left(\mathrm{m}^{3} \mathrm{~m}^{-3}\right)$, macroporosidade $\left(\mathrm{m}^{3} \mathrm{~m}^{-3}\right)$, microporosidade $\left(\mathrm{m}^{3} \mathrm{~m}^{-3}\right)$, densidade do solo $\left(\mathrm{kg} \mathrm{dm}^{-3}\right)$ e diâmetro médio ponderado $(\mathrm{mm})$ em função dos tratamentos e profundidades

\begin{tabular}{|c|c|c|c|c|c|c|}
\hline \multirow{2}{*}{ Fatores } & \multirow{2}{*}{$\begin{array}{c}\mathrm{MO}^{1} \\
\mathrm{~g} \mathrm{dm}^{-3}\end{array}$} & $\mathrm{PT}^{2}$ & Macroporos & Microporos & \multirow{2}{*}{$\begin{array}{c}\mathrm{DS}^{3} \\
\mathrm{~kg} \mathrm{dm}^{-3}\end{array}$} & \multirow{2}{*}{$\begin{array}{c}\mathrm{DMP}^{4} \\
\mathrm{~mm}\end{array}$} \\
\hline & & \multicolumn{3}{|c|}{$\mathrm{m}^{3} \mathrm{~m}^{-3}$} & & \\
\hline & \multicolumn{6}{|c|}{ Caracterização (1992) } \\
\hline $0-0,10 \mathrm{~m}$ & 1,9 & 0,33 & 0,07 & 0,26 & 1,55 & - \\
\hline $0,10-0,20 \mathrm{~m}$ & 1,7 & 0,33 & 0,08 & 0,25 & 1,69 & - \\
\hline \multirow[t]{2}{*}{$0,20-0,40 \mathrm{~m}$} & 1,6 & 0,35 & 0,08 & 0,27 & 1,74 & - \\
\hline & \multicolumn{6}{|c|}{ Profundidade } \\
\hline $0-0,10 \mathrm{~m}$ & 11,0 & $0,40 \mathrm{a}$ & $0,14 \mathrm{a}$ & 0,26 & $1,51 \mathrm{a}$ & $1,25 \mathrm{a}$ \\
\hline $0,10-0,20 \mathrm{~m}$ & 7,0 & $0,36 \mathrm{~b}$ & $0,09 \mathrm{~b}$ & 0,25 & $1,66 \mathrm{~b}$ & $0,92 \mathrm{~b}$ \\
\hline \multirow[t]{2}{*}{$0,20-0,40 \mathrm{~m}$} & 6,0 & $0,34 \mathrm{~b}$ & $0,07 \mathrm{c}$ & 0,26 & $1,58 b$ & $0,76 b$ \\
\hline & \multicolumn{6}{|c|}{ Tratamentos } \\
\hline Testemunha (solo exposto) & $3,0 \mathrm{~b}$ & 0,37 & 0,09 & 0,28 & 1,75 & 0,88 \\
\hline Solo mobilizado & $8,0 \mathrm{a}$ & 0,39 & 0,11 & 0,27 & 1,60 & 0,95 \\
\hline Mucuna preta & $12,0 \mathrm{a}$ & 0,34 & 0,10 & 0,24 & 1,48 & 0,70 \\
\hline Guandu/Feijão de porco & $8,0 \mathrm{a}$ & 0,37 & 0,10 & 0,27 & 1,62 & 1,04 \\
\hline Calcário + mucuna preta & $10,0 \mathrm{a}$ & 0,38 & 0,11 & 0,27 & 1,63 & 1,03 \\
\hline Calcário + guandu/feijão de porco & $8,0 \mathrm{a}$ & 0,38 & 0,11 & 0,27 & 1,60 & 1,02 \\
\hline Calcário + gesso + mucuna preta & $10,0 \mathrm{a}$ & 0,34 & 0,09 & 0,25 & 1,48 & 1,24 \\
\hline \multirow[t]{2}{*}{ Calcário + gesso + guandu/feijão de porco } & $8,0 \mathrm{a}$ & 0,34 & 0,10 & 0,24 & 1,51 & 1,03 \\
\hline & \multicolumn{6}{|c|}{ Teste F } \\
\hline Profundidade & $17,59^{*}$ & $8,81^{*}$ & $28,46^{*}$ & $0,19^{\text {ns }}$ & $1,59^{\star}$ & $9,67^{\star}$ \\
\hline Manejo do solo & $6,95^{\star}$ & $1,18^{\text {ns }}$ & $0,87^{\text {ns }}$ & $0,09^{\text {ns }}$ & $1,0^{\text {ns }}$ & $1,36^{\text {ns }}$ \\
\hline Profundidade $\mathrm{x}$ manejo & $1,02^{\text {ns }}$ & $0,63^{\text {ns }}$ & $0,71^{\text {ns }}$ & $0,77^{\text {ns }}$ & $0,67^{\text {ns }}$ & $1,19^{\text {ns }}$ \\
\hline CV (\%) & 32,31 & 19,41 & 26,46 & 19,41 & 20,06 & 47,12 \\
\hline
\end{tabular}

1 - matéria orgânica; 2 - porosidade total; 3 - densidade do solo; 4 - diâmetro médio ponderado

Médias seguidas de mesma letra nas colunas, não diferem estatisticamente entre si dentro de cada fator pelo teste de Tukey a $5 \%$ de probabilidade. ns não significativo; * ${ }^{*}$ ignificativo a 5 \% pelo teste $\mathrm{F}$

A correção do solo foi baseada na caracterização química da área experimental. A aplicação de calcário para elevar a saturação por bases a $70 \%$ foi efetuada empregando-se a quantidade de $18,5 \mathrm{~kg}$ de calcário por parcela $\left(1,8 \mathrm{t} \mathrm{ha}^{-1}\right)$ (parcelas com calcário somente) e, no caso das parcelas com calcário e gesso, houve a substituição de $20 \%$ do $\mathrm{CaO}$ do calcário pelo $\mathrm{CaO}$ do gesso, aplicando-se 5,2 kg de gesso e 13,8 kg de calcário por parcela $\left(0,52\right.$ e $1,38 \mathrm{t} \mathrm{ha}^{-1}$, respectivamente), ambos incorporados ao solo sendo utilizado calcário dolomítico com PRNT de 70\%; em 1996 foi novamente realizada a correção do solo com base na análise química, para os tratamentos com calcário e calcário mais gesso. A correção foi efetuada nos casos em que a saturação por bases estava inferior a $60 \%$, objetivando-se elevá-la a $70 \%$.

De 1992 a 1996 foram semeadas as espécies de adubo verde uma vez por ano e, no início do florescimento foram roçadas e deixadas na superfície; em janeiro de 1997 foi semeada a cultura do milho (Zea mays L.) em toda a área experimental utilizandose a semente AG 405 e $250 \mathrm{~kg} \mathrm{ha}^{-1}$ da fórmula 4-30-10 mais 0,3\% de zinco, sem aplicação de calcário; em junho de 1998 foi semeada a aveia-preta (Avena strigosa Schieb) o que originou uma boa germinação, porém, por falta de água, a cultura não resistiu; finalmente, em fevereiro de 1999 foi semeada a
Brachiaria decumbens Stapf estando, portanto, há cinco anos na área.

A amostragem do solo foi realizada em 2003 para determinação da porosidade total e densidade do solo, sendo coletadas amostras indeformadas em anéis volumétricos com capacidade de $10^{-4} \mathrm{~m}^{3}$ nas profundidades de $0-0,10,0,10-0,20 \mathrm{e}$ 0,20-0,40 m. A microporosidade foi determinada em mesa de tensão e correspondeu à umidade volumétrica da amostra submetida a uma tensão de 0,006 MPa, após saturação. A porosidade total e a densidade do solo foram obtidas pelo método do cilindro volumétrico, segundo EMBRAPA (1997) e a macroporosidade por diferença entre a porosidade total e a microporosidade.

As medidas de resistência do solo à penetração foram realizadas com o auxílio de penetrógrafo nas profundidades de 0-0,15 m, 0,15-0,30 m, 0,30-0,45 m e 0,45-0,60 m. O teor de água no solo foi determinado pelo método da pesagem (EMBRAPA, 1997), quando as amostras eram coletadas simultaneamente às medidas de resistência do solo à penetração, nas mesmas profundidades.

Para análise da estabilidade de agregados em água utilizouse o método de Angers \& Mehuys (1993) e os resultados foram representados pelo diâmetro médio ponderado (DMP). Obteve- 
se o teor de carbono orgânico total pelo método Walkley-Black, para o cálculo da matéria orgânica (EMBRAPA, 1997). A taxa de infiltração de água do solo foi determinada pelo método dos anéis concêntricos (Bertrand, 1965), nos quais as primeiras cinco leituras foram realizadas em intervalos de um minuto e as demais em intervalos de cinco minutos até atingir a taxa constante de infiltração. O modelo matemático empregado para descrever a infiltração acumulada foi a equação de Kostiakov (1932).

A produção de matéria seca da braquiária foi avaliada em setembro e novembro de 2003 e janeiro e março de 2004, usando uma área útil de $1,0 \mathrm{~m}^{2}$ em quatro pontos por parcela, com altura de corte de 0,03 e 0,20 m. A massa de matéria seca foi obtida após secagem em estufa de ventilação forçada, na temperatura média de $60-70{ }^{\circ} \mathrm{C}$, até atingir massa constante, sendo expressa em $\mathrm{kg} \mathrm{ha}^{-1}$.

Os dados foram submetidos à análise de variância e as médias comparadas pelo teste de Tukey a 5\% de probabilidade pelo programa SAS.

\section{RESULTADOS E DisCUSSÃO}

Todos os atributos físicos em estudo apresentaram diferenças significas em relação à profundidade, com exceção da microporosidade (Tabela 2). Os valores médios da macroporosidade, diâmetro médio de agregados e porosidade total, foram maiores na profundidade de $0-0,10 \mathrm{~m}$ na qual, como há uma concentração maior do sistema radicular da Brachiaria decumbens, maior adição de matéria orgânica (resíduos culturais e efeito dos adubos verdes), provavelmente ocorreu melhoria na estrutura do solo promovendo o aumento do diâmetro médio de agregados com consequente aumento da porosidade total e macroporosidade do solo. Resultados semelhantes foram observados por Rodrigues et al. (2007), estudando a dinâmica da regeneração do subsolo de áreas degradadas dentro do bioma cerrado.

O valor médio da macroporosidade na profundidade de 0-0,10 m está acima do valor considerado ótimo para o desenvolvimento do sistema radicular (Tabela 2). Tormena et al. (2008) relataram que o valor mínimo de macroporosidade para que não seja prejudicada a aeração e o desenvolvimento do sistema radicular, é de $0,10 \mathrm{~m}^{3} \mathrm{~m}^{-3}$. Resultados semelhantes foram observados por Mendes et al. (2006), os autores afirmam que avaliações da qualidade do solo para os atributos físicos em áreas degradadas devem ocorrer na profundidade de até $0,10 \mathrm{~m}$. O valor médio da microporosidade não apresentou diferença em profundidade concordando com os resultados obtidos por Rodrigues et al. (2007).

Observou-se a ocorrência de aumento da densidade do solo da camada superficial para a subsuperfície, porém, na profundidade de 0-0,10 m verifica-se redução da densidade do solo em comparação com as demais camadas (Tabela 2). Em 1992, a área em estudo apresentava valor de densidade do solo superior aos tratamentos estudados, concordando com os resultados obtidos por Alves \& Souza (2008). Naturalmente, o aumento da densidade do solo em profundidade no perfil do solo ocorre devido à diminuição do teor da matéria orgânica e, também, em virtude da massa das camadas de solo sobrejacentes, ocasionando o aumento deste atributo; resultados semelhantes foram observados por Souza \& Alves (2003).

O menor valor médio de densidade do solo encontra-se na profundidade de $0-0,10 \mathrm{~m}$, melhorando a distribuição de poros nesta profundidade (Tabela 2). As leguminosas, segundo Auler et al. (2008) pela adição de carbono ao solo, contribuem na agregação das partículas e mais intensamente na sua fertilidade. Kitamura et al. (2008) também verificaram diminuição da densidade do solo e aumento no volume total de poros, em área degradada, por meio da utilização de adubos verdes e lodo de esgoto. Os autores afirmam que o cultivo de adubos verdes acelera a recuperação do solo, com efeitos mais sensíveis na superfície.

A estabilidade de agregados na profundidade de $0-0,10 \mathrm{~m}$ foi superior à das demais camadas estudadas, ocorrendo o mesmo com o teor de matéria orgânica no solo (Tabela 2). Mendes et al. (2006) verificaram, estudando a recuperação de áreas degradadas com a utilização de plantas de cobertura, valores superiores de DMG e DMP na profundidade de 0-0,10 m. O maior valor de DMP na profundidade de 0-0,10 m é função principalmente da permanência de resíduos orgânicos na superfície do solo os quais se decompõem pela ação de microorganismos, resultando na formação de inúmeros compostos importantes na cimentação e estabilização dos agregados. Segundo Silva \& Mielniczuk (1997), as gramíneas, por apresentarem maior densidade de raízes e melhor distribuição do sistema radicular no solo, contribuem para sua formação e estabilidade e podem ser usadas como plantas recuperadoras da estrutura do solo em áreas degradadas porém a consorciação de gramíneas e leguminosas é mais eficiente na reagregação do que somente leguminosas ou só gramíneas.

Segundo Albuquerque et al. (2003), a aplicação de calcário e gesso pode promover alterações químicas e eletroquímicas do solo com reflexos negativos na floculação de argila no solo pela calagem, causando diminuição na estabilidade de agregados. Observou-se que os tratamentos com calagem e gessagem não promoveram redução da estabilidade de agregados; ao contrário, verificou-se ligeiro aumento no DMP para os tratamentos que receberam calcário e gesso, juntamente com uma planta de cobertura (Tabela 2).

O teor de água no solo obtido no momento da avaliação da resistência do solo à penetração, não foi influenciado pelos sistemas de manejo do solo e diferentes profundidades estudadas (Tabela 3). Verificaram-se, para a resistência do solo à penetração, diferenças significativas, tanto para os sistemas de manejo do solo como para as profundidades estudadas e para a interação. Resultados semelhantes foram observados por Campos \& Alves (2006), avaliando a resistência do solo à penetração de um solo em recuperação sob sistemas agrosilvopastoris.

Os tratamentos calcário + guandu/feijão de porco, calcário + gesso + mucuna preta e calcário + gesso + guandu/feijão de porco, proporcionaram menores valores para resistência do solo à penetração em relação aos demais tratamentos estudados (Tabela 3). Esses resultados evidenciaram tendência de redução da resistência do solo à penetração nos tratamentos em que se utilizaram adubos verdes e calcário e calcário + gesso. Este 
Tabela 3. Valores médios de resistência do solo à penetração $(\mathrm{MPa})$, teor de umidade do solo $\left(\mathrm{kg} \mathrm{kg}^{-1}\right) \mathrm{e}$ taxa de infiltração constante $\left(\mathrm{mm} \mathrm{h}^{-1}\right)$ para os tratamentos e profundidades estudados

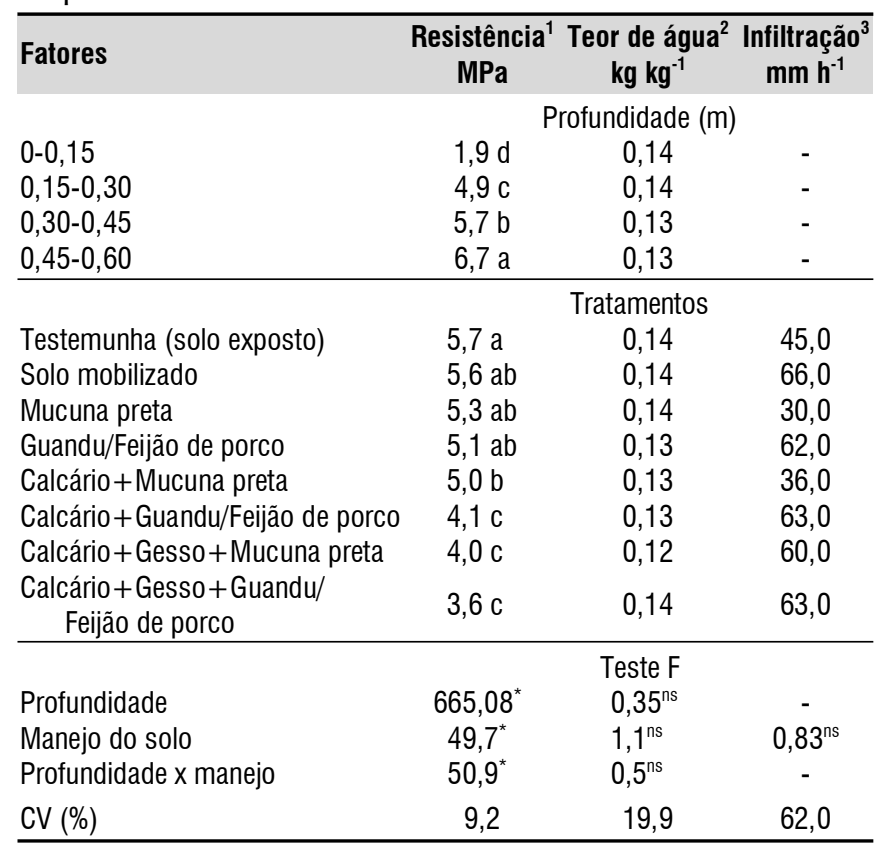

1 - resistência do solo à penetração; 2 - teor de água no solo; 3 - taxa de infiltração constante. Médias seguidas de mesma letra nas colunas não diferem estatisticamente entre si dentro de cada fator pelo teste de Tukey a $5 \%$ de probabilidade. ${ }^{\text {ns }}$ ão significativo; ${ }^{*}$ significativo a $5 \%$ pelo teste $\mathrm{F}$

fato está relacionado, provavelmente, ao maior teor de matéria orgânica e, em consequência, à maior estabilidade de agregados proporcionados pelas plantas de cobertura, porém, Nascimento et al. (2005), avaliando o efeito de leguminosas nos atributos físicos e carbono orgânico de um Luvissolo, observaram que as leguminosas mantiveram inalterados os atributos do solo estudados nas condições edafoclimáticas do experimento, no período de três anos. Em profundidade a resistência do solo à penetração foi menor na camada de $0-0,15 \mathrm{~m}$, aumentando nas outras camadas, resultados coerentes com os valores de macroporosidade e porosidade total.

Os valores médios da taxa constante de infiltração estão muito abaixo dos resultados encontrados para a condição natural do solo (cerrado - $330 \mathrm{~mm} \mathrm{~h}^{-1}$ ). Observa-se que não ocorreu diferença entre os tratamentos estudados (Tabela 3). A infiltração de água indica diferenças no comportamento hidrodinâmico do solo em função da alteração de sua estrutura. Considerando-se que a infiltração de água reflete as condições físicas do solo, como estrutura, porosidade e ausência de camadas compactadas, deduz-se que os tratamentos aplicados não proporcionaram modificação quanto à estrutura do solo e movimento de água ao longo do perfil. Resultados semelhantes foram observados por Alves et al. (2007), estudando a densidade do solo e infiltração de água como indicadores da qualidade física de um Latossolo Vermelho distrófico em recuperação.

A área em estudo apresentava, em 1992, em média densidade do solo igual a $1,65 \mathrm{~kg} \mathrm{dm}^{-3}$ e macroporosidade de $0,08 \mathrm{~m}^{3} \mathrm{~m}^{-3}$ (Tabela 2). A área encontrava-se em estágio avançado de degradação, uma vez que densidades na faixa de 1,6 a 1,8 $\mathrm{kg} \mathrm{dm}^{-3}$ e macroporosidade do solo abaixo de $0,10 \mathrm{~m}^{3} \mathrm{~m}^{-3}$ impedem o desenvolvimento de raízes. Após 13 anos da aplicação dos tratamentos não se verificou efeito dos tratamentos na recuperação da área de empréstimo em subsuperfície. Bouma (1991) afirma que a recuperação de atributos físicos em áreas degradadas em subsuperfície é lenta quando comparada com a superfície, em que a quantidade de resíduo é bem maior e, com isso, ocorre maior incorporação de matéria orgânica.

Os sistemas de manejo do solo adotados não influenciaram significativamente na porosidade do solo, na densidade do solo, no diâmetro médio de agregados nem na taxa constante de infiltração (Tabelas 2 e 3). Os valores médios dos atributos físicos do solo indicam que os tratamentos estão apresentando uma lenta evolução na sua recuperação. Segundo Modesto et al. (2009), o retorno de áreas degradadas ao estado anterior pode não ocorrer ou ser extremamente lento. A recuperação dos solos degradados até atingir as condições próximas às originais, quando com sistemas de uso, é pouco provável, evento que pode precisar de dezenas e ate mesmo centenas de anos. Alves \& Souza (2008) afirmam que a recuperação da estrutura dos solos é lenta e deve ser reconstruída no tempo por meio do manejo de solo e plantas. Low (1955) estimou que foram necessários 100 anos de pastos com gramíneas para aumentar a quantidade de agregados $>2,0 \mathrm{~mm}$ de 12 para $73 \%$ em área degradada.

Ocorreu aumento significativo da produção de matéria seca da braquiária no tratamento com calcário + gesso + guandu/ feijão de porco, em relação aos tratamentos calcário + gesso + mucuna preta, solo mobilizado, guandu/feijão de porco e calcário + guandu/feijão de porco (Tabela 4). A produção de matéria seca no tratamento calcário + gesso + guandu/feijão de porco superou em $167 \mathrm{~kg} \mathrm{ha}^{-1}$ o observado no solo mobilizado e de $212 \mathrm{~kg} \mathrm{ha}^{-1}$ ao tratamento com guandu/feijão de porco devido à ação conjunta do calcário e gesso, mais as leguminosas tropicais. Mesquita et al. (2004) verificaram, estudando o

Tabela 4. Valores médios da produção de matéria seca da braquiária $\left(\mathrm{kg} \mathrm{ha}^{-1}\right)$ em função dos tratamentos, época e altura de corte estudado

\begin{tabular}{lc}
\hline \multicolumn{1}{c}{ Tratamentos } & $\begin{array}{c}\text { Produção de matéria } \\
\text { seca }\left(\mathbf{~ k g ~ h a ~}^{-1}\right)\end{array}$ \\
Solo mobilizado & $378 \mathrm{cde}$ \\
Mucuna preta & $455 \mathrm{abc}$ \\
Guandu/Feijão de porco & $333 \mathrm{de}$ \\
Calcário+Mucuna preta & $491 \mathrm{ab}$ \\
Calcário+Guandu/Feijão de porco & $320 \mathrm{e}$ \\
Calcário+Gesso+Mucuna preta & $426 \mathrm{bcd}$ \\
Calcário+Gesso+Guandu/Feijão de porco & $545 \mathrm{a}$ \\
\hline Época & $1423 \mathrm{a}$ \\
Setembro/03 & $308 \mathrm{~b}$ \\
Novembro/03 & $149 \mathrm{c}$ \\
Janeiro/04 & $123 \mathrm{c}$ \\
Março/04 & $104 \mathrm{c}$ \\
Maio/04 & $615 \mathrm{a}$ \\
\hline Altura de corte (m) & $227 \mathrm{~b}$ \\
0,03 & \\
0,20 &
\end{tabular}
de probabilidade pelo teste de Tukey 
Tabela 5. Desdobramento da interação tratamento x época x altura ( $k g$ ha $\left.^{-1}\right)$, obtido para a avaliação da produção de matéria seca da braquiária de um solo em recuperação

\begin{tabular}{|c|c|c|c|c|c|c|c|c|}
\hline \multirow{3}{*}{ Tratamento } & \multicolumn{2}{|c|}{ Setembro/2003 } & \multicolumn{2}{|c|}{ Novembro/2003 } & \multicolumn{2}{|c|}{ Janeiro/2004 } & \multicolumn{2}{|c|}{ Março/2004 } \\
\hline & \multicolumn{8}{|c|}{ Altura de corte (m) } \\
\hline & 0,03 & 0,20 & 0,03 & 0,20 & 0,03 & 0,20 & 0,03 & 0,20 \\
\hline & \multicolumn{8}{|c|}{ Tratamento } \\
\hline $\mathrm{SB}^{1}$ & $2379 \mathrm{Ba}$ & $359 \mathrm{Aa}$ & $307 \mathrm{BCb}$ & $137 \mathrm{Ba}$ & $111 A b$ & $139 \mathrm{Aa}$ & $111 \mathrm{Ab}$ & $75 \mathrm{Aa}$ \\
\hline $\mathrm{MP}^{2}$ & $2251 \mathrm{Ba}$ & $546 \mathrm{Aa}$ & $205 \mathrm{Cb}$ & $187 \mathrm{Bb}$ & $92 \mathrm{Ab}$ & $172 \mathrm{Ab}$ & $54 \mathrm{Ab}$ & $156 \mathrm{Ab}$ \\
\hline $\mathrm{G} / \mathrm{FP}^{3}$ & $1950 \mathrm{Ca}$ & $228 \mathrm{Aa}$ & $209 \mathrm{Cb}$ & $205 \mathrm{Ba}$ & $124 \mathrm{Ab}$ & $224 \mathrm{Aa}$ & $86 \mathrm{Ab}$ & $182 \mathrm{Aa}$ \\
\hline $\mathrm{C}+\mathrm{MP}^{4}$ & $3350 \mathrm{Aa}$ & $282 \mathrm{Aa}$ & $282 \mathrm{BCb}$ & $165 \mathrm{Ba}$ & $122 A b$ & $179 \mathrm{Aa}$ & $67 \mathrm{Ab}$ & $245 \mathrm{Aa}$ \\
\hline $\mathrm{C}+\mathrm{FP}^{5}$ & $1861 \mathrm{Ca}$ & $306 \mathrm{Aa}$ & $201 \mathrm{Cb}$ & $200 \mathrm{Ba}$ & $91 \mathrm{Ab}$ & $173 \mathrm{Aa}$ & $102 \mathrm{Ab}$ & $120 \mathrm{Aa}$ \\
\hline $\mathrm{C}+\mathrm{Ge}+\mathrm{MP}^{6}$ & $1971 \mathrm{Ca}$ & 367 Aab & $687 \mathrm{Ab}$ & $595 \mathrm{Aa}$ & $157 \mathrm{Ac}$ & $221 \mathrm{Ab}$ & $127 \mathrm{Ac}$ & $231 \mathrm{Ab}$ \\
\hline $\mathrm{C}+\mathrm{Ge}+\mathrm{G} / \mathrm{FP}^{7}$ & $3367 \mathrm{Aa}$ & $412 \mathrm{Aa}$ & $592 \mathrm{Ab}$ & $340 \mathrm{ABa}$ & $97 \mathrm{Ac}$ & $178 \mathrm{Aa}$ & $34 \mathrm{Ac}$ & $129 \mathrm{Aa}$ \\
\hline
\end{tabular}

Médias seguidas de letras iguais maiúsculas na coluna e minúscula na linha (para a mesma altura de corte), não diferem estatisticamente entre si, pelo teste de Tukey a $5 \%$.

1 - solo mobilizado; 2 - mucuna preta; 3 - guandu/feijão de porco; 4 - calcário +mucuna preta; 5 - calcário +guandu/feijão de porco; 6 - calcário +gesso+mucuna preta; 7 - calcário+gesso+guandu/ feijão de porco

estabelecimento de pastagem consorciada com aplicação de calcário e gesso, que a substituição de parte do calcário pelo gesso melhorou o ambiente radicular, translocando cálcio, magnésio e enxofre para a camada de 0,15-0,30 m de profundidade, com aumento significativo na produção da braquiária.

Todos os tratamentos que tiveram aplicação de gesso aumentaram a produção de massa seca da braquiária (Tabela 4). Segundo Caires et al. (1998), uma alternativa para a correção do subsolo ácido e degradado é a aplicação superficial de gesso agrícola onde, mesmo sem incorporação e pelo fato do gesso ser relativamente solúvel, o mesmo pode movimentar-se no perfil do solo, com a influência do teor de água no solo. Quando alcança o subsolo o gesso aumenta o suprimento de cálcio e reduz a toxidade de $\mathrm{Al}^{3+}$, propiciando melhoria do subsolo e melhor crescimento radicular nessa camada permitindo maior eficiência na obtenção de água e nutrientes.

Os manejos calcário + gesso + guandu/feijão de porco $(\mathrm{C}+\mathrm{Ge}+\mathrm{G} / \mathrm{FP})$ e calcário + mucuna preta $(\mathrm{C}+\mathrm{MP})$ proporcionaram maiores produtividades de matéria seca de braquiária em relação aos demais tratamentos, quando a altura de corte foi efetuada a 0,03 m do solo (Tabela 5). Nascimento et al. (2003) notaram, avaliando o efeito do uso de leguminosa em atributos do solo, melhorias em uma área degradada. O mesmo comportamento ocorreu com a altura de corte de 0,20 m do solo, ou seja, respeitando a altura de pastejo houve efeito significativo entre os tratamentos, quando a produção do tratamento com calcário + gesso + mucuna preta se destacou em relação à produção do solo mobilizado e não diferiram dos demais tratamentos.

Para a interação tratamento $\mathrm{x}$ época $\mathrm{x}$ altura, observou-se que no corte realizado em setembro, na altura de $0,03 \mathrm{~m}$, os tratamentos com calcário + gesso + guandu/feijão de porco e calcário + mucuna preta e, em novembro/2003, na altura de 0,03 $\mathrm{m}$, os tratamentos calcário + gesso + mucuna preta e calcário + gesso + guandu/feijão de porco proporcionaram maiores produtividades de matéria seca (Tabela 5). Para a altura de corte de 0,20 m, em novembro/2003, o tratamento calcário + gesso + mucuna preta proporcionou maiores produtividades de matéria seca que os demais tratamentos, com exceção do tratamento com calcário + gesso + guandu/feijão de porco cujas produtividades foram semelhantes. Rodrigues et al. (2007) constataram, estudando a dinâmica da regeneração do subsolo de áreas degradadas dentro do bioma cerrado, que a braquiária apresentou resultados satisfatórios na recuperação de áreas degradadas, com os atributos físicos nas áreas em recuperação aproximando-se da área com cerrado natural.

\section{CONClusões}

1. Conclui-se, após 11 anos de intervenção, que os tratamentos adotados recuperaram, embora de forma lenta, os atributos físicos do subsolo exposto.

2. Os efeitos da recuperação do solo atingiram a profundidade de $0-0,10 \mathrm{~m}$.

\section{LITERATURA CITADA}

Albuquerque, J. A.; Bayer, C.; Ernani, P. R.; Mafra, A. L.; Fontana, E. C. Aplicação de calcário e fósforo e estabilidade da estrutura de um solo ácido. Revista Brasileira de Ciência do Solo, v.27, p.799-806, 2003.

Alcântara, F. A.; Furtini Neto, A. E.; Paula, M. B.; Mesquita, H. A.; Muniz, J. A. Adubação verde na recuperação da fertilidade de um Latossolo Vermelho-Escuro degradado. Pesquisa Agropecuária Brasileira, v.35, p.277-288, 2000.

Alves, M. C.; Souza, Z. M. Recuperação de área degradada por construção de hidroelétrica com adubação verde e corretivo. Revista Brasileira de Ciência do solo, v.32, p.2505-2516, 2008.

Alves, M. C.; Suzuki, L. G. A. S.; Suzuki, L. E. A. S. Densidade do solo e infiltração de água como indicadores da qualidade física de um Latossolo Vermelho distrófico em recuperação. Revista Brasileira de Ciência do Solo, v.31, p.617-625, 2007.

Angers, D. A.; Mehuys, G. Aggregate stability to water. In Carter, M.R. (ed.). Soil sampling and methods of analysis. Boca Raton: Canadian Society of Soil Science, Lewis Publisher, 1993. p.651-657.

Aquino, A. M.; Silva, R. F; Mercante, F. M.; Correia, M. E. F.; Guimarães, M. F.; Lavelle, P. Invertebrate soil macrofauna under different ground cover plants in the no-till system in the Cerrado. European Journal of Soil Biology, v.44, p.191197, 2008. 
Auler, P. A. M.; Fidalski, J.; Pavan, M. A.; Neves, C. S. V. J. Produção de laranja 'pêra' em sistemas de preparo de solo e manejo nas entrelinhas. Revista Brasileira de Ciência do Solo, v.32, p.363-374, 2008.

Bertrand, A. R. Rate of water intake in the field. In: Black, C.A. (ed.). Methods of soil analysis. Part 1. Madison: American Society of Agronomy, 1965. p.197-208.

Bouma, J. Influence of soil macroporosity on environmental quality. Advances in Agronomy, v.46, p.2-36, 1991.

Caires, E. F.; Chueiri, W. A.; Madruga, E. F.; Figueiredo, A. Alterações de características químicas do solo e resposta da soja ao calcário e gesso aplicados na superfície em sistema de cultivo sem preparo do solo. Revista Brasileira de Ciência do Solo, v.22, p.27-34, 1998.

Campos, F. S.; Alves, M. C. Resistência à penetração de um solo em recuperação sob sistemas agrosilvopastoris. Revista Brasileira de Engenharia Agrícola e Ambiental, v.10, p.759764, 2006.

Campos, F. C.; Alves, M. C.; Souza, Z. M.; Pereira, G. T. Atributos físico-hídricos de um Latossolo após a aplicação de lodo de esgoto em área degradada do Cerrado. Ciência Rural, v.41, p.796-803, 2011.

Chada, S. S.; Campello, E. F. C.; Faria, S. M. Sucessão vegetal em uma encosta reflorestada com leguminosas arbóreas em Angra dos Reis, RJ. Revista Árvore, v.28, p.801-809, 2004.

Demattê, J. L. I. Levantamento detalhado dos solos do Campus Experimental de Ilha Solteira. Piracicaba: ESALQ/USPDepartamento de Solos, Geologia e Fertilidade, 1980. 44p.

EMBRAPA - Empresa Brasileira de Pesquisa Agropecuária. Centro Nacional de Pesquisa de Solos. Manual de métodos de análise de solos. 2.ed. Rio de Janeiro: Embrapa CNPS, 1997. 212p. Documentos, 1

EMBRAPA - Empresa Brasileira de Pesquisa Agropecuária. Centro Nacional de Pesquisa de Solos. Sistema brasileiro de classificação de solos. Rio de Janeiro: Embrapa CNPS, 2006. 306p.

Ferreira, W. C.; Botelho, S. A.; Davide, A. C.; Faria, J. M. R. Avaliação do crescimento do estrato arbóreo de área degradada revegetada à margem do Rio Grande, na Usina Hidrelétrica de Camargos, MG. Revista Árvore, v.31, p.177185, 2007.

Kitamura, A. E.; Alves, M. C.; Suzuki, L. G. A. S.; Gonzalez, A. P. Recuperação de um solo degradado com a aplicação de adubos verdes e lodo de esgoto. Revista Brasileira de Ciência do Solo, v.32, p.405-416, 2008.
Köppen, W. Grundriss der krimakunde. Berlin: Walter de Gruyter, 1931.390p.

Kostiakov, A. N. On the dynamics of the coefficient of waterpercolation in soils and on the necessity for studying it from a dynamic point of view, purposes of amelioration. In: International Society Soil Science, 6, 1932, Paris. 1932. p.1721. Part A

Low, A. J. Improvements in the structural state of soils under leys. Journal of Soil Science, v.6, p.179-199, 1955.

Mendes, F. G.; Melloni, E. G. P.; Melloni, R. Aplicação de atributos físicos do solo no estudo da qualidade de áreas impactadas, em Itajubá-MG. Cerne, v.12, p.211-220, 2006.

Mesquita, E. E.; Fonseca, D. M.; Pinto, J. C.; Nascimento Junior, D.; Pereira, O. G.; Venegas, V. H. A.; Moreira, L. M. Estabelecimento de pastagem consorciada com aplicação de calcário, fósforo e gesso. Ciência e Agrotecnologia, v.28, p.428-436, 2004.

Modesto, P. T.; Scabora, M. H.; Colodro, G.; Maltoni, K. L.; Cassiolato, A. M. R. Alterações em algumas propriedades de um Latossolo degradado com uso de lodo de esgoto e resíduos orgânicos. Revista Brasileira de Ciência do Solo, v.33, p.1489-1498, 2009.

Nascimento, J. T.; Silva, I. F.; Santiago, R. D.; Silva Neto, L. F. Efeito de leguminosas nas características químicas e matéria orgânica de um solo degradado. Revista Brasileira de Engenharia Agrícola e Ambiental, v.7, p.457-462, 2003.

Nascimento, J. T.; Silva, I. F.; Santiago, R. D.; Silva Neto, L. F. Efeito de leguminosas nos atributos físicos e carbono orgânico de um Luvissolo. Revista Brasileira de Ciência do Solo, v.29, p.825-831, 2005.

Rodrigues, G. B.; Maltoni, K. L.; Cassiolato, A. M. R. Dinâmica da regeneração do subsolo de áreas degradadas dentro do bioma Cerrado. Revista Brasileira de Engenharia Agrícola e Ambiental, v.11, p.73-80, 2007.

Silva, I. F.; Mielniczuk, J. Ação do sistema radicular de plantas na formação e estabilização de agregados do solo. Revista Brasileira de Ciência do Solo, v.21, p.113-117, 1997.

Souza, Z. M.; Alves, M. C. Propriedades físicas e teor de matéria orgânica em um Latossolo Vermelho de cerrado sob diferentes usos e manejos. Acta Scientiarum Agronomy, v.25, p.27-34, 2003.

Tormena, C. A.; Fidalski, J.; Rossi Júnior, W. Resistência tênsil e friabilidade de um Latossolo sob diferentes sistemas de uso. Revista Brasileira de Ciência do Solo, v.32, p.33-42, 2008. 